\title{
Enrollee Choices After Their Health Plans Are Terminated: Default Effects Versus Persistent Preferences Faculty Research Working Paper Series
}

\section{Anna Sinaiko}

Harvard T. H. Chan School of Public Health

\section{Richard Zeckhauser}

Harvard Kennedy School

December 2016

RWP16-055

Visit the HKS Faculty Research Working Paper Series at:

https://research.hks. harvard.edu/publications/workingpapers/Index.aspx

The views expressed in the HKS Faculty Research Working Paper Series are those of the author(s) and do not necessarily reflect those of the John F. Kennedy School of Government or of Harvard University. Faculty Research Working Papers have not undergone formal review and approval. Such papers are included in this series to elicit feedback and to encourage debate on important public policy challenges. Copyright belongs to the author(s). Papers may be downloaded for personal use only. 


\title{
Enrollee Choices After Their Health Plans Are Terminated: Default Effects Versus Persistent Preferences
}

\author{
Anna Sinaiko \\ Richard Zeckhauser \\ Harvard University
}

December 13, 2016

\section{Acknowledgements}

The authors gratefully acknowledge funding from the National Institute of Aging through P01 AG032952, The Role of Private Plans in Medicare. We thank Alan Zaslavsky for expert guidance in estimating and implementing propensity-score-based weighting. Jeff Souza and Lauren Riedel provided excellent programming and research assistance. Joseph Newhouse, Adam Oliver, Cass Sunstein, Joshua Schwarzstein, and participants at the 2014 Conference on Behavioral Economics, Law and Health Policy at the Petrie-Flom Center at Harvard Law School, the American Society of Health Economists (ASHEcon) $5^{\text {th }}$ Biennial Conference in Los Angeles CA in June 2014, and at the Academy Health 2015 Annual Research Meeting in Minneapolis $\mathrm{MN}$, provided useful suggestions. 


\section{Abstract}

Behavioral economic research has established that defaults, one form of nudge, powerfully influence choices. In most policy contexts, all individuals receive the same nudge. We present a model that analyzes the optimal universal nudge when individuals differ in their preferences, different individuals should make different choices, and there is a cost to resist a nudge. Our empirical focus is on terminated choosers, individuals whose prior choice becomes no longer available. Specifically, we examine the power of defaults for individuals who had enrolled in Medicare Advantage with drug coverage and had their plans discountinued. Should these terminated choosers fail to actively choose another Medicare Advantage plan, they are automatically defaulted into fee-for-service Medicare absent drug coverage. Overall, the rate of transition for TCs to FFS Medicare is low, implying that original preferences and status quo bias overpowered the default. Black TCs were more susceptible to the default than non-blacks. Increasing numbers of Americans are choosing plans in health insurance exchange settings such as Medicare, the Affordable Care Act (ACA), and private exchanges. Plan exits and large numbers of TCs are inevitable, along with other forms of turmoil. Any guidance and defaults provided for TCs should attend to their past revealed preferences.

Keywords: Default Effects, Health Insurance Choice, Health Insurance Marketplaces, Status Quo Bias, Nudges, Optimal Nudges, Medicare Advantage, Affordable Care Act, Medicare, Terminated Plans 


\section{Introduction}

The Patient Protection and Affordable Care Act (ACA) of 2010 established state and federal insurance marketplaces. Its twin objectives were to expand access to affordable, highquality health insurance and to foster a competitive marketplace for health insurance. Since the ACA's implementation, health insurance markets for individuals have experienced dramatic changes, including in the range of plan offerings, plan affordability, and impact on competition in the marketplace. (See for example Gabel et al 2014, Dafny, Hendel et al 2015; Dafny, Gruber et al 2015.) Product entry and exit is a natural part of any dynamic marketplace. Whereas in some markets, in steady state, fluctuation of product offerings may be minimal (e.g., pension bond fund markets), health insurance marketplaces, which rely at least in part on public financing and regulation, experience far greater turnover.

Such turnover activity has become a salient side effect on ACA exchanges (Cox et al 2015; Cox and Semanskee 2016). Plan terminations stemmed from several sources. For example, in 2016, 12 of the 23 non-profit state-level health care cooperatives ("co-ops") which insured more than 700,000 individuals (Armour 2016), and in some marketplaces had a significant share of the market (40\% market share in Colorado) exited marketplaces (King 2015). United Healthcare and Aetna, two of the largest national health insurers in the US, prior to the 2016 presidential election announced their plans to exit marketplaces in 2017 , impacting up to 1.5 million individuals who enrolled in the two company's plans and generating additional unrest due to significant coverage of these terminations in the national media (Cox and Semanskee 2016; Pear 2016). At the time of this writing (in December 2016), it is impossible to predict the future for the ACA marketplaces under President Trump and a Republican Congress. But one can confidently predict that whatever the future, there will be vast numbers of individuals whose health plans will no longer be available.

Despite the earthquakes that strike health insurance markets, to our knowledge there has been no examination of the health insurance choices made by enrollees who have 
previously made a choice that subsequently becomes unavailable. We label these individuals "terminated choosers" (TCs). This lack of attention to TCs contrasts sharply to the vast literature on initial choice in public and private health insurance exchange settings. TCs raise several important underlying questions. They have enrolled in health insurance in a prior period; following their plan termination will they enroll again, and where? If not, what happens to them? How does the architecture of the insurance exchange affect these outcomes and consumer welfare?

This paper examines the impact of a critical aspect of marketplace choice architecture a terminated chooser's default option - on ultimate plan enrollment outcomes. In any decisionmaking context, the "default option" is a form of a nudge, and is the selection that will be made automatically if an individual fails to make an active choice. In most marketplaces, following notice of plan termination enrollees can actively select a new health plan during the subsequent open enrollment period. However TCs who fail to actively choose a new plan face a default that can range from enrollment in another selected plan, random assignment to another plan, or going without insurance (no insurance).

Research has established the power of defaults for outcomes in a range of decisions, from savings and investments to organ donations (Madrian and Shea 2001; Beshears et al. 2009; and Johnson and Goldstein 2003). However, these studies focus overwhelmingly on how defaults affect the decisions of individuals who are selecting options for the first time, individuals whom we label original choosers. In contrast, TCs represent a different set of clients, because they actively selected an option in an earlier period. As such, three oft-mentioned explanations for the power of defaults (1) the presence of anxiety (Camerer et al. 2005; and Frank 2007); (2) the perception that the default is endorsed by authorities (such as financial planners, personnel officers, and policy makers) who "know what is best for us" (Goldstein et al. 2008); and (3) the view that the default is the status quo, implying that any alternative would be a significant and regrettable error of commission (Samuelson and Zeckhauser 1988) may apply less forcefully to 
TCs. The question of whether defaults are sufficiently powerful to strongly influence the choices of terminated choosers is unknown.

The choices of TCs in health insurance marketplaces are important for three reasons.

First, health insurance is increasingly offered via market-like settings (e.g., Medicare Advantage and Medicare Part D, ACA marketplaces, private exchanges) and many health insurance plans terminate, implying that the future enrollment of TCs is an important policy issue. Second, unlike the case of original choosers, TCs have revealed information about their preferences for a health plan through their prior selection. When defaults differ significantly from these prior choices, TCs are tugged by two competing behavioral tendencies: those tendencies linked to defaults versus those associated with the combination of persistent preferences and status quo bias. Greater understanding of the choices TCs make under these circumstances can improve our understanding of consumer choice dynamics in health insurance marketplaces, and probably more generally. Third, public health insurance marketplaces often establish defaults for enrollees in terminated health plans. In most policy contexts, all individuals receive the same default. Understanding the power of defaults for TCs, and by extension how to choose appropriate defaults to maximize the welfare of TCS is important. ${ }^{1}$

To address these questions, this paper first presents a model that analyzes the optimal default nudge when individuals differ in their preferences, implying that different individuals should make different choices, and there may be a cost to resist a nudge. We then analyze a group of terminated choosers in a health insurance exchange setting: clients in Medicare Advantage health insurance contracts that are cancelled. ${ }^{2}$

Medicare Advantage (MA) plans are private health plans in which beneficiaries can enroll in lieu of traditional, fee-for-service Medicare either when they become eligible for

\footnotetext{
1 We are here judging the effects of this nudge on the clients; we are not assessing whether the health insurance system gains or loses as a result of TC choices.

${ }^{2}$ Throughout the program's history, Part $\mathrm{C}$ has had several different names. The name, Medicare Advantage, dates to the Medicare Modernization and Improvement Act of 2003.
} 
Medicare (typically, at age 65), or subsequently during annual open-enrollment periods. Although this is a different population than the one that enrolls in ACA marketplaces, these beneficiaries, like ACA beneficiaries, face a choice among a set of regulated plans offered at the local level (e.g., county). Similarly, the plans for MA and for ACA beneficiaries vary in benefit design, generosity, and physician networks. Also like non-group health plans, MA plans sometimes terminate either because they do not meet some new regulatory standard or because the health insurer chooses to stop offering them, usually due to expected losses going forward. Then, their enrollees are terminated.

If TCs of Medicare Advantage plans do not actively elect other MA plans, they are defaulted into traditional fee-for-service (FFS) Medicare. One might expect defaults to powerfully affect the choices of TCs, because insurance choices involve both uncertainty and high stakes, two conditions that have been shown to intensify errors in decision-making (Frank 2007). However, terminated choosers in MA at one point chose MA rather than enroll in traditional Medicare, which was also the default when they made their original choice. This choice both actively signaled their preferences for a benefits package that differs significantly from fee-for-service Medicare and demonstrated their ability to overcome a default to make an active choice. Moreover, status quo bias--the tendency of individuals to continue with a current choice rather than switch--would also create a force that counteracts the influence of the default. In sum, the expected outcome for TCs in MA is unclear when the default opposes revealed preferences and status quo bias.

This paper exploits a natural experiment: Due to legislated changes in plan payment and regulation passed in 2003, large numbers of plans exited the MA program at uneven rates across the U.S in the second half of the 2000s. This led large numbers of beneficiaries to become TCs. For this class of individuals we examine the competing forces of preferences, status quo bias, and the default where the default nudged individuals away from the alternative they had actively chosen for themselves in a prior period. 
This paper proceeds as follows. Section 2 discusses behavioral economic theory and the general literature on health plan choice, default effects, and other competing forces. Section 3 presents a model analyzing the optimal default when individual preferences vary. Section 4 describes the Medicare Advantage program, the evidence on Medicare beneficiary plan choices, and this study's data and methods. Section 5 presents our empirical analysis of enrollment outcomes for TCs versus other MA beneficiaries. Section 6 concludes.

\section{Health Plan Selection and Frictions: Theory and Evidence}

The implicit neoclassical model of consumer health-plan selection has consumers assess the attributes of each alternative health plan, including benefit coverage and limits, provider network, plan quality, and total cost (premium plus out-of-pocket cost as a function of expenditures). They then select their best alternative. ${ }^{3}$ While consumers cannot know their future health care needs with any certainty, they have prior beliefs about the distribution of those needs, and the costs of alternative treatments given alternative health plans. Consumers are assumed to understand the relative importance of a health plan's attributes, and to weigh them rationally according to their own best interests. Implicitly, they use a multi-attribute utility function (Keeney and Raiffa 1976). Thus, the plans they choose maximize their expected utility over the potential states of the world. A few advanced consumers will compute expected utility using a benefit-cost approach. They will enroll in the health plan where their expected net benefit, defined as expected benefit across potential states of the world less expected costs across potential states of the world, is greatest. Everyday consumers will intuitively and roughly weigh the advantages and disadvantages of alternative plans.

\footnotetext{
${ }^{3}$ Quality includes health outcome measures, process measures, structural measures, and consumer satisfaction scores.
} 
At regular intervals, consumers re-evaluate their plan choices in response to changes in plan attributes and their own health status, and switch plans if better alternatives become available. Under this model, consumers' plan choices provide information about their preferences among health insurance plans. ${ }^{4}$

A substantial theoretical and empirical literature finds that consumers frequently behave contrary to this model of health insurance choice. This suggests in turn that some of its key underlying assumptions are not satisfied. One important deviation is that consumers have been shown to be strongly influenced by defaults, often as a result of inertia. Moreover, such passive acceptance may not reflect conscious or meaningful choices. Rather it may be the product of other forces, such as procrastination (Beshears et al. 2008). Seminal articles find evidence of a powerful default effect in the highly consequential area of financial planning and savings decisions (Madrian and Shea 2001), and in organ-donation decisions (Johnson and Goldstein 2003).

The well-documented power of defaults underlies the "nudge approach" to improving individuals' outcomes, where choice architecture is designed recognizing that behavioral decisions are likely to lead to personally suboptimal choices (Thaler and Sunstein 2009). Nudges can take a great variety of forms. By requiring a reading passage or presenting an image before a choice is made, an individual might be nudged to behave in a more moral, more generous, or more long-term fashion. Commercial entities frequently use such priming nudges to get consumers to focus on particularly appealing features of their products. If decisions are of particular but often overlooked importance, there might be a spotlight nudge, requiring

\footnotetext{
${ }^{4}$ More generally, plan choices due to consumer preferences drive important phenomena in health insurance markets. A prime example is the adverse selection of sicker individuals into more generous plans, which is a phenomenon that undermines the ability of health insurance markets to deliver care efficiently (Arrow 1963; Cutler and Reber 1998).
} 
individuals to review material or participate in a conversation before making a choice. Requiring an individual to make an active choice is a mild form of spotlighting.

Nudgers bring all sorts of motives when seeking to influence the decisions of others. Some are purely self interested: I will be better off if I can get you to choose B rather than A. Some are purely paternalistic: Choice B is better for you, but you are more likely to choose A absent my nudge. Many nudges are designed to secure socially superior outcomes when externalities are important. Nudges to conserve energy or return aluminum cans fall in this category. Some nudges push toward one choice, but spotlight nudges are often designed merely to get individuals to choose more wisely for themselves.

Defaults are a widely employed form of nudge. For example, in an effort to get individuals to save more for retirement, companies structure retirement benefits so that employees are defaulted into automatic savings plans. When this happens, the vast majority simply remain enrolled. Actions by a few to escape from a default are perceived to be implicit evidence of true preferences.

Status quo bias, which describes disproportionate adherence to previous choices, is another force observed to interfere with the assumptions in our simple choice model. Status quo bias was first identified as affecting health insurance choices in a study of enrollees in employer-sponsored health plans (Samuelson and Zeckhauser 1988). Such persistence to prior choices may reflect a quasi-rational reliance on an informal assessment of search and transition costs combined with uncertainty about alternative options. Or such persistence may simply reflect that options change slowly and that people's preferences remain fairly consistent. However, these rationalizations for persistence may not apply in many circumstances. Status quo bias also has the potential to lead clients away from rational decision processes. Thus, individuals may give weight to sunk costs and use current decisions as a means to justify past choices. They may suffer an endowment effect, in which something already possessed takes on an exaggerated value. They may seek to avoid regret; sticking with their initial choice helps 
them to avoid learning that that choice was poor. They may weight errors of commission (switching plans when they should not) far more than errors of omission (failing to switch when they should) (Samuelson and Zeckhauser 1988).

In health insurance marketplaces, a terminated chooser has already made a prior choice. When that choice differs substantially from the default, a tug-of-war ensues for TCs. Tugging on one side is the combination of status quo bias and the persistence of the individual's original revealed preference for their health plan; tugging on the other side is the default, e.g., the nudge. The outcome is a matter of both theoretical and policy interest. Moreover, a nudge that goes against an individual's deliberate past choice has little normative justification. We now move from the specific to the general and present a stylized model of an optimal nudge.

\section{An Optimal Nudge When Preferences Vary}

In the following the socially concerned nudger is taken to be male; the nudgee female.

Preferences. Each individual has a preference between two alternatives, A and B. Her preference ranges on a scale from -1 to 1 . At 1 , she strongly prefers A. At -1 , she strongly prefers B. Thus, -0.2 would be a mild preference for B. Denote the preference value by $p$. Nudges. A nudge pushes an individual toward one alternative or the other. A nudge is calibrated on the same scale. Thus, a 1 is a strong nudge toward A; a -1 is a strong nudge toward B. Denote the nudge value by $n$.

Susceptibility. Individuals are more or less susceptible to nudges. The opposite of susceptibility is resistance. Susceptibility is measured from 0 to 1 . This gives the weight to be placed on the nudge versus the preference. Denote the susceptibility value by $s$.

The choice value, $\mathrm{C}$, is given by:

$$
\mathrm{C}=p(1-s)+n s
$$

Thus, if $s$ is small, preference plays the predominant role; if $s$ is large, $n$ plays a major role. If $\mathrm{C}$ is positive, then the individual picks $\mathrm{A}$. If it is negative, she picks $\mathrm{B}$. In a more 
elaborate model, an error term would be added to $\mathrm{C}$, to represent, for example, behavioral factors.

Distributions in the Population. Individuals differ in their preferences and their susceptibilities to nudges. For expositional ease, assume independence on these two variables, though in real life that will often not be the case.

The distribution of preferences is $f(p)$. The distribution of susceptibilities is $g(s)$.

The central question for the nudger, who is seeking to maximize expected welfare taking both direct individual utilities and societal resources into account, ${ }^{5}$ is the magnitude of nudge to use. Posit that it is to be applied to the general society, and that nudges must be general; they cannot be tailored to specific individuals. Thus, the nudger may be the government choosing a default between Medicare and Medicare Advantage, or a commercial firm trying to nudge people on its product offerings.

For expositional ease, assume that the individual's preference is for $A$, but the nudger wishes to push him toward B. There are two prime cases to consider. Case I occurs when there is straight paternalism. Thus, the government may find that people tend to eat unhealthy product $A$ rather than healthier product $B$. Representative examples would be requiring restaurants to publish their calorie counts, imposing a tax on sugar, or prohibiting the sale of soft drinks in schools.

Case II occurs when the nudger has a private preference interest in the outcome, quite apart from the preferences of the individual. Thus, it might be a commercial company trying to increase profits, or the government trying to shuttle individuals to a health plan that is less expensive for it to provide. Under Case II, the nudgers may have a further divide, depending on who is doing the nudging. Presumably, the commercial company would be interested solely in its profits, though it would take customer satisfaction into account to the extent that it affected

\footnotetext{
${ }^{5}$ Of course, societal resources can only come from individuals, and resource expenditures would ultimately reduce individuals' utilities.
} 
long-term profits. The government, presumably, would have dual goals, individual satisfaction as well as government costs. Thus, the government would not wish to have its nudge override strong consumer preferences. Our presentation focuses on the case where the nudger, who is seeking to maximize expected welfare, has some concern with catering to consumer preferences.

Some nudges can be resisted by individuals merely by mildly resisting them. Thus, an individual who has a strong preference for product A may stick with it even if advertising, or advisories, or a salesman pushes them strongly towards B. However, to overcome some nudges may entail an actual cost. This happens frequently with defaults, when for example, to overcome a default, one need merely check a different box, or make a single brief phone call. In other cases, the process to overcome requires substantial time and effort. Difficulty overcoming a default also occurs when one has no idea of how to do so, or because the time to do so is far in the future, so people do not take notice when they are defaulted. (Introductory subscriptions to a magazine, which renew automatically unless you call to cancel, represent a prime example of this latter case.) The costs involved in overcoming a default nudge represent dead weight losses.

Consider now the nudger who seeks the optimal nudge, $n^{*}$ to maximize expected welfare. For this illustration, it will be the government. The nudger knows $f(p)$ and $g(s)$. It also knows that there is an unrecognized loss of $k$ for every individual who chooses $A$. Note $k$ may arise because individuals incur a health cost they ignore or because the government incurs a financial cost if $A$ is chosen rather than $B$, and individuals do not internalize that cost. Finally, there is a deadweight loss of $d$ for every individual who is subjected to the nudge, but still chooses A. Thus, $d$ is the cost of overcoming the nudge. Both $k$ and $d$ are calibrated in the same units as $p$. The government, as stated, would like to maximize expected net benefits. To reiterate, an individual will choose $\mathrm{A}$ if their $\mathrm{C}$ value, $\mathrm{C}=p(1-s)+n s$, is strictly positive. (Assume that indifferent people, $\mathrm{C}=0$, follow the nudge.) 
Total welfare is given by:

$$
\int_{S}\left\{\int_{C \geq 0}(p-k-d) f(p) d p+\int_{C<0}(-p) f(p) d p\right\} g(s) d s
$$

Thus, the government will pick $n^{\star}$ to maximize (2), the expected payoff to a randomly chosen individual.

Fuller presentations will examine how $n^{*}$ changes depending on $f(p), g(s)$, the values of $k$ and $d$, etc. For example, if $f(p)$ has considerable density at high values, that is lots of people strongly like $\mathrm{A}, g(s)$ takes on mostly modest values, and if $d$ is consequential, then a strong nudge, indeed any nudge, may diminish welfare. This is because a large fraction of the population will overcome the nudge, and thus incur consequential cost $d$.

Many additional factors would enter an optimal nudge model. For example, it would seem plausible, of course, that the cost of overcoming a nudge would depend on the magnitude of the nudge, that $d$ would be an increasing function of $|\mathrm{n}|$. If so, as $d$ increases, the optimal nudge would diminish. ${ }^{6}$

An optimal nudge might change over time. Say that you nudge a population once. Some people follow the nudge. Others do not. Presumably, nudge followers are disproportionately individuals with low values of $p$, though some with higher values of $p$ but also high values of $s$ will also be nudged.

If nothing changed, of course, a second nudge of the same value would have no effect. This would not be the case if there is error in computing $C,{ }^{7}$ so that an individual who usually would have switched did not do so the first time. Alternatively, $p$ and $s$ might drift around a bit, say following a random walk, so a second-round nudge would change behavior. Even in light of

\footnotetext{
${ }^{6}$ Two factors lead to this result. First, as d increases, the benefits of switching the marginal individual diminish. Second, the cost to those not switching increases. A reduction in nudge is beneficial on both grounds.

"If the nudge were a default, for example, the individual might have missed the opportunity to "correct" it. That's how magazines make money by offering really cheap introductory subscriptions.
} 
these possibilities, we would still expect those who resisted the nudge initially to be disproportionately high in $p$.

Under reasonable regularity conditions, this high $p$ result for initial resisters would imply that for this group the optimal nudge would be weaker the second time around. A greater percentage of the folks who would be subject to it would optimally stick with choice $A$. The converse also applies. In a situation where people had to choose a second time, the optimal nudge for those who initially succumbed would be increased.

We now turn to apply this broad framework for nudges to the particular empirical problem of defaults for TCs in health insurance markets. We examine the results of a nudge of TCs from Medicare Advantage through a default to Traditional Medicare, where TCs can only overcome that nudge if they make an active choice back to MA. We first describe Medicare Advantage in more detail, and then examine that problem empirically.

\section{Study Context, Data, and Methods}

\subsection{Medicare Advantage}

One of the most consequential choices an elderly person can make is whether to enroll in traditional Medicare, which provides fee-for-service health insurance, or in a Medicare Advantage plan, which gives beneficiaries a choice among private health plans that offer benefits that are at least actuarially equivalent to traditional Medicare. ${ }^{8,9}$ The Medicare enrollment process typically favors traditional Medicare, as evidenced by the way beneficiaries

\footnotetext{
${ }^{8}$ During the initial enrollment period of seven months around one's $65^{\text {th }}$ birthday, beneficiaries who choose to join traditional Medicare are defaulted into Part A (hospital insurance); they have the options to enroll in Part B (physician services) and Part D (prescription drug coverage). Delaying enrollment in Part $B$ and/or Part $D$ results in late-enrollment penalties. The majority of beneficiaries in traditional Medicare also enroll in a private Medicare supplemental plan during this period (for example, Medigap), thus covering the co-pays and deductibles that are not covered by traditional Medicare.

${ }^{9}$ Beneficiaries choose among MA plans offered in the service area in which they live, usually their county. There are some exceptions for enrollees in MA plans who either move temporarily or move into a plan's designated "continuation area."
} 
are defaulted into the hospital insurance component of the program (known as Part A) and by the way information is presented in the Medicare and You package. ${ }^{10}$ Unlike traditional Medicare, most MA plans are managed-care plans in which beneficiaries accept access to a limited physician network and also accept having their care managed (through prior authorization and gatekeeping) in exchange for more generous benefits. However, some MA plans are private fee-for-service plans. MA plans can offer prescription drug coverage through Medicare Part D (MA-PD plans) or not (MA-only plans).

The availability of MA plans has ebbed and flowed over the program's history. Prior to 2003, most MA plans were offered by Health Maintenance Organizations (HMOs). From 19972003, following the passage of Balanced Budget Act of 1997, many plans were terminated. Enrollment in MA fell dramatically, from 16\% of Medicare beneficiaries in 1999 to $12 \%$ in 2002. In many cases, a return to traditional Medicare was the only option facing these TCs, as approximately $20 \%$ of TCs in during this time had no other MA plan available after their plan exited (Gold et al. 2004).

In 2003, the Medicare Modernization and Improvement Act increased payment rates paid to MA plans. The result was that, for the rest of the decade, the average MA plan payment was 12 to 14 percent higher per beneficiary than the estimated cost of coverage for similar people in traditional Medicare (MedPAC 2010). From 2003-2008, these higher payments coupled with regulatory provisions led to the establishment of plans offering richer benefit packages than traditional Medicare. These more favorable plans offered reduced out-of-pocket costs (OOPC) alongside extra benefits (MedPAC 2007; MedPAC 2009). As would be expected, the supply of MA plans, in terms of the number and variety of options such as Preferred

\footnotetext{
${ }^{10}$ For example, the 2015 materials explain that there is a choice between traditional Medicare and Medicare Advantage in Section 1, titled "Learn how Medicare Works." However, information about Medicare Advantage and its plans doesn't come until page 75 of the Medicare and You booklet (which is Section 5), after "Signing Up for Medicare Parts A \& B" (Section 2), "Find out if Medicare covers your test, service or item" (Section 3), and "What's Original Medicare?" (Section 4).
} 
Provider Organization (PPO) plans and Private Fee-for-Service (PFFS) plans, expanded substantially. Like HMOs, PPOs are managed-care plans that restrict physician networks. PFFS plans from the period of 2003-2008 were very similar to traditional Medicare, offering feefor-service coverage, but without imposing any provider restrictions. In the most recent era of the Medicare program (since 2006), beneficiaries have been able to switch their coverage options during the open enrollment period each year (typically starting in mid-October and lasting six weeks). Beneficiaries in traditional Medicare can elect to switch their prescription drug plans within traditional Medicare or to switch from traditional Medicare into MA.

Beneficiaries in MA can shift across MA plans or switch into traditional Medicare.

From 2008 forward, the total number of MA plans decreased, for a few reasons. The Patient Protection and Affordable Care Act (ACA) of 2010 reduced payments to MA plans relative to traditional Medicare. This legislative measure led some HMO and PPO plans to exit the market (Afendulis et al. 2012). The anticipated payment reductions, along with provisions in the Medicare Improvements for Patients and Providers Act (MIPPA) of 2008 that imposed a network requirement on PFFS plans, made such plans less attractive; fewer were offered. Some counties experienced much greater rates of MA plan exits than others, though, in contrast to the earlier era in the late 1990s, beneficiaries in all counties continued to have access to at least one MA plan of each plan type from 2007-2010 (MedPAC 2011). Importantly for the purposes of our study, these plan exits were not likely to have been driven by demand-side behavior (for example, by lack of beneficiary demand for MA). In fact, MA enrollment continued to grow steadily through November 2015 (MedPAC 2016), the latest date available.

\subsection{Medicare Beneficiary Plan Choice}

A growing body of evidence reveals behavior suggesting that some Medicare beneficiaries enroll in a plan that is suboptimal for them. A significant example is status quo bias in the Medicare market. Individuals who decide to enroll in MA tend to remain in the program over long periods of time. Yet few enrollees in traditional Medicare switch into MA 
(Sinaiko et al. 2013; Afendulis et al 2014). In theory, this could merely be because the enrollees in MA and traditional Medicare had different preferences or health risks. However, the Sinaiko analysis shows that beneficiaries who remain in traditional Medicare forgo significant savings in the sum of premiums and out-of-pocket costs, an example of what we label "money-wasting." Medicare beneficiaries, being elderly and often unhealthy, may often face diminished decisionmaking and cognitive capabilities (Hanoch and Rice 2006; Agarwal et al. 2008), placing them at higher risk for biased or inadvertent, and therefore possibly poor, choices. In a changing world, such as the medical marketplace, the simplest poor choice to make with an expensive purchase, such as medical insurance, is to fail to contemplate the choices and simply to continue with the current plan.

Choice can be impaired in other ways. McWilliams et al. (2011) find evidence consistent with "choice overload." They show that rates of enrollment in MA increased as plan choices increased up to 15 , then plateaued with 16 to 30 plan choices, and then declined when beneficiaries had more than 30 choices available. The current authors find as well that beneficiaries with reduced cognitive function, as would be expected, were less responsive than their peers to the generosity of MA benefits when choosing between traditional Medicare and MA.

In the Medicare Part D program, a beneficiary chooses among prescription drug plans in an exchange setting. Ketcham et al (2012) and Ketcham et al (2015) use longitudinal data to demonstrate that at least some Part $D$ enrollees were able to improve their choices in their second, third and fourth year of the program, particularly when the potential gains from switching plans were high. They identify this evidence in a complex choice environment, which suggests that these beneficiaries had strong existing preferences for Part D plans. However, money-wasting choices in Part $\mathrm{D}$, defined as plans that do not roughly minimize the sum of a beneficiary's premiums plus out-of-pocket costs for a given level of risk, have been observed in significant numbers among all enrollees and among TCs specifically. These inferior choices 
arise in part because beneficiaries over-value plan premiums relative to all out-of-pocket costs when making their selections (Abaluck and Gruber 2011; Abaluck and Gruber 2013). Low rates of Part D enrollment by those eligible to enroll and receive the low-income subsidy, a program that makes this drug coverage and prescription drugs essentially free to beneficiaries, reflect obvious, and extreme money-wasting choices (Kuye et al. 2013).

The existing literature on Medicare describes a variety of factors that interfere with plan selection and switching, including status quo bias, choice overload, strongly disparate weighting of different elements of cost, and straightforward money-wasting. It also discusses beneficiary characteristics that make them susceptible to these behavioral biases. In this regard, the evidence suggests that TCs are among those making the most effective choices in the Medicare program. First, TCs consciously chose to enroll in MA in at the outset rather than accept the traditional Medicare default, thereby demonstrating their preference for receiving health insurance through a MA plan. Second, a higher proportion of MA as opposed to traditional Medicare clients enroll in Medicare Part D, which offers prescription drug coverage at heavily subsidized rates, and thus reflects an effective choice. Given these facts, we would expect TCs to be less susceptible than most to a default into TM.

\subsection{Data}

We obtained data from the Centers for Medicare and Medicaid services (CMS) on the entire population of elderly (age 65+) Medicare beneficiaries in the United States who were enrolled in an MA plan that included prescription drug coverage (known as an MA-PD plan) for the years 2006-2011. ${ }^{11}$ Henceforth, for ease of exposition, when we refer to Medicare Advantage or MA plans or clients, we mean MA-PD enrollees.

\footnotetext{
${ }^{11}$ Due to data limitations (described in more detail below), we were only able to distinguish a plan exit from a plan merger or a consolidation in MA-PD plans. Therefore, we excluded MA-only plans from this analysis.
} 
We excluded beneficiaries who became eligible for Medicare due to disability, those dually eligible for Medicaid, the long-term institutionalized, and those enrolled with an insurer outside of their county of residence. We also excluded enrollees in Medicare Advantage employer plans and Special Needs Plans (SNPs) because these beneficiaries face significantly different enrollment choices and incentives. Finally, to focus the analysis on the plan choices and outcomes in locales with robust MA marketplaces, we restricted the analysis to beneficiaries who lived in the 200 US counties with the largest elderly populations and who were enrolled in the three most common types of MA contracts: HMOs, PPOs, and PFFS. This sample included 17,651,389 elderly-person-year observations. The data included information on beneficiaries' dates of birth, genders, races (black or non-black), zip codes of residence, the MA contracts in which they were enrolled, and whether they continued to be enrolled in MA or switched to traditional Medicare in each month of the study period.

Generally, insurers contract with Medicare to offer a specific type of plan (HMO, PPO, or PFFS) in a county, but many insurers offer multiple plans with different names and variable benefits under each contract. Our data included identifiable contract-level, but not plan-level, enrollment information for each beneficiary. The data also included an encrypted plan-level ID for each beneficiary which, importantly for this study, allowed us to link to information on marketlevel plan changes at the county level (such as consolidations, mergers, exits, or no change). Because we did not have information on the default options for beneficiaries whose MA plans went through a merger or consolidation, we dropped these beneficiaries ( $2.4 \%$ of observations) from our analysis. Our final study sample, following this exclusion, included 17,226,866 personyear observations.

\subsection{Cohorts}

We analyzed the characteristics and transitions of TCs over three pairs of years: 20062007, 2009-2010, and 2010-2011. We did not examine transitions in 2007-2008 or 2008-2009, 
because very few MA contracts terminated in those intermediate years; as a consequence they provided too few TCs to study.

Our study group of TCs includes all beneficiaries in our sample who were enrolled in a plan and MA-PD contract that was offered in their county of residence in the first year of the period, but that was no longer offered in the second year. ${ }^{12}$ We conducted this analysis at the contract level for two reasons. First, contract exits often leave beneficiaries without a substitute nearly identical to the terminated plan, which is not the case with plan exits. ${ }^{13}$ Second, we know the default for these clients, namely enrollment in traditional Medicare.

We analyzed the choices of two other types of MA beneficiaries in our sample: voluntary switchers and stayers. Voluntary switchers are those who chose to either switch to a new MA contract or switch into traditional Medicare, although their prior MA contract continued to be available had they wanted to stay enrolled in it. Stayers are beneficiaries who did not act during open enrollment, and therefore by choice or by inaction were re-enrolled the following year in their existing plan. Both voluntary switchers and stayers faced circumstances different from those of terminated choosers, given that TCs had no choice but to switch plans. Finally, we also examined the choices of original choosers, who were beneficiaries who turned 65 in the

\footnotetext{
${ }^{12} \mathrm{MA}$ plans that are exiting a market must notify beneficiaries 60 days before the end of the year that their coverage will end on December $31^{\text {st }}$ of that year. Exiting plans must inform beneficiaries that they can change to TM or choose another MA plan from a provided list of plans available in the service area. The beneficiaries remain in the Medicare program regardless of what they choose. Beneficiaries have from the time they are notified until approximately two months after their coverage ends to make these elections, though enrolling by December $31^{\text {st }}$ ensures no interruption in coverage. Beneficiaries electing to return to traditional Medicare will have neither prescription drug coverage nor any Medicare supplemental coverage (Medigap) to pay the costs that traditional Medicare doesn't cover, unless they actively choose to enroll in those plans at that time. Beneficiaries who do not enroll in Part $D$ at that time will incur a financial penalty if they later choose to do so.

${ }^{13}$ When a single plan within a contract exits, a beneficiary may have a choice of another plan offered by the same carrier under the same contract that offers covered benefits, cost-sharing requirements, and physician networks strikingly similar to the exiting plan. We would expect choices made by these TCs who have very similar alternatives available to consciously choose MA more than others. Unfortunately, we cannot observe when this circumstance occurs in our data. Moreover, in some cases these TCs might be defaulted into the similar plan alternative still available within their existing contract. We thus restrict the analysis to TCs in plans for which the entire contract is terminated, where staying in MA requires that these TCs select a plan in a new contract, and where the default if they fail to make a choice is to be enrolled in traditional Medicare.
} 
second year of the two-year period and who then enrolled in MA or traditional Medicare for the first time, the latter perhaps due to a default into traditional Medicare.

\subsection{Descriptive Analyses}

First, we present descriptive statistics on the enrollment outcomes for these four groups: TCs, voluntary switchers, stayers, and original choosers and their rates of switching into traditional Medicare and their rates of switching into different types of MA contracts for HMO enrollees in 2006-07, for HMO enrollees in 2009-10, and for PFFS enrollees in 2009-10. In 2010, the widespread exit of PFFS contracts created many TCs. However, due to data limitations, we could not observe the types of MA contracts in which voluntary switchers and TCs enrolled in 2011; neither could we examine the choices across plans for beneficiaries who remained in MA in 2011. Therefore, we only examined transitions from MA to traditional Medicare during the $2010-2011$ period, both by TCs and by voluntary switchers.

\subsection{Statistical Analyses}

Terminated choosers differ from voluntary switchers and from stayers because TCs, but for the termination of their plan, would have included both stayers and voluntary switchers. Given the termination, we cannot distinguish between these two types in enrollment claims data. Comparing TCs to either group alone would be an unfair comparison.

To identify as best possible appropriate comparisons for the choices of terminated choosers, and to bring balance to our terminated and comparison populations, we used a weighting approach that uses a propensity score approach (Hirano and Imbens 2001; and Kurth et al. 2006). to account for observable differences between terminated choosers and nonterminated choosers (including both voluntary switchers and stayers) and to bring the nonterminated chooser population into balance with the terminated choosers. We then analyzed differences in plan outcomes between this weighted comparison group of non-terminated choosers and the outcomes for terminated choosers. 
This approach first employs a logit model to estimate the propensity for being a terminated chooser on the basis of age, gender, race (black or not), and county. We control for county because plan payment rates are set at the county level, and thus could affect a health plan's propensity to withdraw, and therefore a beneficiary's probability of being a terminated chooser. Moreover, because all residents within a county face the same plan choices, our results are not driven by differences in underlying plan choice sets facing TCs and non-TCs. ${ }^{14}$ To account for changes in payments and differences in preferences for insurance plan types, models were run separately by year and MA plan type (HMO or PFFS). We applied the coefficients from this model to the data to estimate the probability, $p$, that each beneficiary in a non-terminated contract would be a terminated chooser. We then generate a set of weights, where each terminated chooser was assigned a weight equal to 1 , and non-terminated choosers were assigned a weight of (p/1-p). (Hirano and Imbens 2001; and Kurth et al. 2006). ${ }^{15}$ The weighted distributions of characteristics of terminated and non-terminated choosers are identical (see Appendix) and weighted analyses therefore adjust for potential confounding due to the individual characteristics included in the propensity score models. ${ }^{16}$

We compared weighted rates of enrollment into traditional Medicare and into MA overall. Among beneficiaries who remained in MA, we compared rates of enrollment across types of MA plans (MA-HMO, MA-PPO, and MA-PFFS). Statistical significance was assessed using Pearson's chi-square test. We also compared differences in rates of enrollment in Part D plans among beneficiaries who switched into traditional Medicare.

\footnotetext{
${ }^{14}$ Beneficiaries in counties that did not experience any plan terminations were excluded from the analysis.

${ }^{15}$ In instances where the number of terminated choosers (the treatment population) was greater than the number of non-terminated choosers (the control population), estimating propensity-score weights in this population would result in a loss in efficiency. Due to the dramatic changes in the PFFS market that began in 2009, this circumstance arose for the PFFS market in a subset of our study counties during the 2009-2010 study period. Therefore, we restricted the 2009 PFFS models to include only counties where there were at least as many non-terminated choosers as terminated choosers.

${ }^{16}$ Others have applied this methodology to analyze the impact of health insurance on health care utilization and on health care spending (see for example McWilliams et al 2007, Zhang et al 2009).
} 


\section{Results}

\subsection{Beneficiary switching and descriptive transitions}

Over the period 2006-2010, nearly 233,000 beneficiaries in MA plans became TCs. ${ }^{17}$ TCs were similar in age, gender, and race to both voluntary switchers and stayers, but were much more likely to have been enrolled in their MA contracts for a shorter duration, one year or less (Table 1). The vast majority of the MA contract exits examined occurred in 2006, 2009, and 2010. The yearly proportion of MA enrollees who switched out their plan increased over the study period, from $8.8 \%$ to $13.8 \%$, and the majority of switchers each year were voluntary switchers (Table 2). Voluntary switchers were more likely than TCs to transition from MA to traditional Medicare following each of those years (Table 3).

Tables $4 \mathrm{a}$ and $4 \mathrm{~b}$ present unadjusted, descriptive data on the transitions of TCs and all other types of beneficiaries: voluntary switchers, stayers, and original choosers. Considering transitions in 2006-2007 (Table 4a), TCs in all plan types were much less likely to transition to traditional Medicare than were voluntary switchers moving out of the same plan types. The transition numbers are $5.2 \%$ vs. $19.5 \%$ for $\mathrm{HMO}$ enrollees, $15.0 \%$ vs. $24.9 \%$ for PPO enrollees, $25 \%$ vs. $41.6 \%$ for PFFS enrollees--though this last category had a very small sample size. Among beneficiaries who were in an MA-HMO in 2006, TCs were more likely to enroll in a PFFS plan than were voluntary switchers. Together, voluntary switchers and TCs who stayed in MA were more likely to enroll in a non-HMO plan than were either stayers (column 7) or original choosers who chose MA (column 8).

By contrast, in 2009, when significant numbers of PFFS plans first exited from MA markets, TCs' higher rate of remaining in MA as compared to voluntary switchers was driven by terminated choosers in PFFS plans. In 2009, a large proportion of terminated choosers had

${ }^{17}$ This figure includes TCs created in all five years of the entire period, though $98 \%$ occurred in 2006 , 2009, and 2010. 
originally enrolled in PFFS plans. In comparison with voluntary switchers from PFFS in 2009, TCs were dramatically more likely to stay in MA in 2010 (85.0\% vs. 41.8\%, Table 4b, column 5 vs. 6). Another large group of terminated choosers in 2009 had originally enrolled in a PPO plan. Here we observe the one instance in which a larger proportion of these beneficiaries transitioned to traditional Medicare than did voluntary switchers from this plan type $(35.3 \%$ vs. 16.1\%, Table 4b column 3 vs. 4). TCs in MA-HMO plans were slightly less likely to transition to traditional Medicare than were voluntary switchers from MA-HMO plans (15.4\% vs. $17.2 \%)$. Again, we observe from 2009-2010 as we did from 2006-2007, that both voluntary switchers and TCs who stayed in MA were more likely to enroll in a non-HMO plan than were stayers (column 7) and original choosers who chose MA (column 8).

\subsection{Statistical Analyses}

It is not possible to draw appropriate inferences about the impact of default policies and the effects of terminated plans, simply based on the results from Section 5.1. That is because neither voluntary switchers, nor stayers, nor original choosers constitute an appropriate comparison group for TCs. This section presents results on plan enrollment outcomes of TCs versus those for a sample of non-terminated choosers that includes both voluntary switchers and stayers, where members of that sample were weighted according to their propensity for being in a terminated plan, thereby creating balance between the two groups.

TCs in our pooled sample were more likely to transition to traditional Medicare than were non-terminated choosers $(11.1 \%$ vs $2.6 \%, \mathrm{p}<0.001)$ (Table 5$)$. This pattern holds both among TCs who were originally enrolled in HMOs and those originally enrolled in PFFS Medicare Advantage plans. TCs were three times more likely to move to traditional Medicare from MA$\mathrm{HMO}$ contracts in 2006, twelve times more likely to move to traditional Medicare from MA-HMO contracts in 2009, and twice as likely to move to traditional Medicare from MA-PFFS contracts in 2009. 
Multiple forces could contribute to these dramatic disparities. One possibility is that status quo bias among individuals whose plans survived led them to stick with their plan going forward. A second is that some TCs were affected by the default into traditional Medicare when traditional Medicare may or may not have been their second choice. We incline to status quo bias of the non-terminated choosers being the principal explanation, as that group's members only switched to traditional Medicare $2.6 \%$ of the time. The switch percentage for TCs to traditional Medicare was $11.1 \%$, implying that the default was hardly determinative.

\subsection{Further analysis of quality of choices and susceptibility to nudges}

TCs who transitioned from MA to traditional Medicare were a distinct minority. No doubt, some of these transitions were voluntary, but some may have been influenced by the default into traditional Medicare. If so, this should be reflected in the differential likelihood that these two groups of TCs chose to enroll in a plan with prescription drug coverage. That is because, prior to their plan termination, all TCs in our sample had selected a Medicare Advantage plan that included a prescription drug plan. Traditional Medicare with Part D or a new Medicare Advantage plan with Part $D$ is much closer to being actuarially equivalent to their plan prior to their termination than is traditional Medicare without Part D. However, traditional Medicare without Part $\mathrm{D}$ is the default. TCs who move into Traditional Medicare must actively enroll in a Part D plan if they are to have prescription drug coverage. Given their original choices, and the heavy subsidies of Part D, we conclude that those TCs transitioning to traditional Medicare without Part D probably made a mistake and suffered expected monetary losses.

We compared the rates of enrollment in a Part D plan among TCs (Table 6). First, the top panel shows that among all TCs, those moving to traditional Medicare were significantly more likely to fail to enroll in a Part D plan than were their peers who actively chose to stay in MA $(20.6 \%$ vs $1.7 \%)$.

The second panel shows the population of TCs who transitioned to Traditional Medicare. Beneficiaries who were male were more likely to fail to enroll in Part D than were women (24.0\% 
vs $19.2 \%, p<0.001)$ as were beneficiaries who were black vs non-black ( $38.7 \%$ vs $20.2 \%$, $\mathrm{p}<0.001$ ). Failing to enroll in a Part $\mathrm{D}$ plan decreases with age and with median household income of the zip code in which beneficiaries reside.

\section{Discussion}

This study investigates the phenomenon of a policy-imposed default versus the forces promoting consistent choices among terminated choosers in health insurance markets. The evidence shows that the default policy associated with contract terminations in Medicare Advantage had a moderate impact on the transitions of beneficiaries in terminated plans from MA to traditional Medicare. TCs were more likely to be enrolled in traditional Medicare in the year following their plan terminations than were non-terminated choosers. However, a very large percentage of TCs took specific action to select new MA plans, following their initial plan's termination. Their active choices to remain in MA likely stemmed from the same preferences that were operating when they originally reviewed the available plans and deliberately chose MA. The persistent preferences of these individuals were perhaps reinforced by status quo bias, which has been shown to exist, for some combination of rational and irrational reasons, among Medicare beneficiaries.

The majority of TCs who transitioned into traditional Medicare from 2009-2010 also showed their ability to choose contrary to a default. Roughly three quarters of them took the active step to enroll in the Part D benefit. The remaining quarter of TCs transitioning to traditional Medicare following their plan termination failed to take up a Part D plan, an outcome in contrast to their prior selection of a MA plan with Part D, suggesting some susceptibility to nudges. Those most susceptible were more likely to be black, male, younger and to live in a zip code with lower median household income. The finding that susceptibility decreases with age is a bit surprising given that aging is associated with cognitive decline which inhibits decisionmaking. However, working in opposition, and presumably prevailing, is the fact that older 
beneficiaries presumably are more likely to need more prescription drugs, and thus benefit more from Part D coverage.

Typically, default rules are used to nudge people away from making errors that might otherwise occur in complex, high-stakes choice environments (for example, with $401 \mathrm{~K}$ plan enrollment), and where the experts are in relatively widespread agreement on which alternative is superior. The default nudge studied here differs dramatically from more traditional policy nudges for two reasons. First, there is no evidence that it was actively designed to promote superior choices for individuals. In fact, the lack of automatic enrollment in Part D leaves beneficiaries who accepted the default substantially worse off in expectation than they would be if they had been able to stay in their prior plan. Second, this nudge pushes individuals towards an option that is quite different than what they had chosen in a prior period. These two features of the default, and therefore their implications for consumer welfare, differ from the vast majority of nudges reported in previous literature.

Why does Medicare include this default? Given that Medicare Advantage costs the government more, and that Part D coverage is heavily subsidized, one possible justification would be that a successful nudge would save the government money. But surely that consideration should be weighed against having beneficiaries choose against their preferred plans. And any government that gets into the business of such nudges has to worry about hurting its overall legitimacy. Rather, the specified default for TCs in Medicare Advantage is likely in place because it mirrors the default for original choosers in the Medicare program, which is traditional Medicare, and it is the most administratively simple to implement.

However, the specified default of TCs to traditional Medicare fails to make use of information about beneficiaries' revealed preferences among plans. A second MA plan is likely 
more similar to the original choice than TM in several consequential ways (e.g., covered benefits, cost-sharing requirements), hence likely to be better suited to the client. ${ }^{18}$

Smart defaults, which take into account individual starting positions, preferences, or expected needs, have been suggested as an alternative to the "benign" default discussed thus far in this paper (Smith et al 2009). Smart defaults have begun to be used in other public programs, ${ }^{19}$ and have been shown to have the potential to achieve large savings for enrollees in Medicare Part D (Zhang et al 2015). ${ }^{20}$

Because of differences in physician networks across health plans, smart defaults would add administrative complexity, but they would be feasible. For example, in Medicare a smart default system could analyze the degree of overlap in physician networks across MA plans in an area; it could then use MA as the default if the overlap reached a certain threshold; below the threshold the default would be TM. An even more sophisticated algorithm could consider the physicians the individual has previously used, and at a more advanced level could even include information about recent diagnoses and the implications for appropriate health-care coverage. The success of these default alternatives would be revealed if we observed that relatively few TCs chose against them.

More generally, the outcomes for terminated choosers in other health-insurance exchange settings should be examined. Nearly 13 million individuals have enrolled in health plans through state or federal health-insurance marketplaces created under the ACA. These

\footnotetext{
${ }^{18}$ By analogy, consider if one had to choose a new car default for an individual who was trading in an SUV that was no longer made. An SUV default would more likely meet his preferences than a sedan. ${ }^{19}$ For example, the California demonstration project to Integrate Care for Dual Eligible Beneficiaries (the Cal MediConnect program) is passively enrolling individuals into health plans using an "intelligent assignment" process that analyzes the individual's recently used providers and matches those providers to the physician networks of participating plans. Individuals will be passively enrolled in the plan that best meets their current circumstances, prioritizing continuity of care. There is a 90-day period when individuals can change plans or opt-out (California Department of Health Care Services 2014). ${ }^{20}$ Zhang et al simulate an "intelligent assignment" algorithm that would assigning Medicare beneficiaries with schizophrenia who are eligible for a low-income subsidy to the least expensive Part D prescription drug plan based on their prior year drug use instead of random assignment to any plan (the current policy) and project savings, on average, of $\$ 387$ per beneficiary.
} 
include many different types of clients: those who were previously insured in individual insurance plans and who presumably have considerable experience selecting plans and navigating the market, and those who were previously uninsured and who likely have very little experience with health insurance. The effects of default policies following plan terminations across these different types of enrollees could differ dramatically. In some ACA marketplaces, TCs who fail to select a new option for coverage lose their health insurance coverage altogether, an outcome that is clearly sub-optimal relative to their prior choice. In 2017 , enrollees in terminated plans purchased through federally-facilitated marketplaces may be automatically enrolled in a new plan (generally the lowest-cost plan of the same product network type), if they don't choose a new plan or actively opt-out of the marketplace (Jost 2016).

Plan enrollment decisions are very consequential for individuals. Increasing numbers of Americans are choosing plans in health insurance exchange settings such as Medicare, the Affordable Care Act (ACA), and private exchanges, and turmoil and large numbers of TCs are inevitable. Whether terminated choosers in these exchanges select and enroll in new plans and how their responses vary based on default policy and previous insurance status, health status, and other characteristics are matters of great policy consequence. Any guidance and defaults provided for TCs should attend to their past revealed preferences. 
Table 1. Characteristics of Stayers vs. Terminated Choosers vs. Voluntary switchers:

MA-PD enrollees in the 200 largest counties in the U.S., $2006-2010$

\begin{tabular}{|c|c|c|c|}
\hline & Stayers & Terminated Choosers & Voluntary Switchers \\
\hline n (person-years) & $15,590,641$ & 232,538 & $1,403,687$ \\
\hline Female & $58.4 \%$ & $57.3 \%$ & $55.8 \%$ \\
\hline Black (vs non-black) & $7.9 \%$ & $7.7 \%$ & $9.1 \%$ \\
\hline \multicolumn{4}{|l|}{ Age } \\
\hline $65-69$ & $27.9 \%$ & $35.3 \%$ & $31.8 \%$ \\
\hline $70-74$ & $25.7 \%$ & $25.3 \%$ & $25.1 \%$ \\
\hline $75-79$ & $21.9 \%$ & $18.5 \%$ & $19.9 \%$ \\
\hline $80-84$ & $14.9 \%$ & $12.4 \%$ & $13.5 \%$ \\
\hline $85+$ & $9.7 \%$ & $8.6 \%$ & $9.8 \%$ \\
\hline \multicolumn{4}{|c|}{$\begin{array}{l}\text { Years enrolled in plan (prior to } \\
\text { switch) }\end{array}$} \\
\hline$<1$ & $13.1 \%$ & $40.8 \%$ & $27.0 \%$ \\
\hline 1 & $13.5 \%$ & $18.4 \%$ & $19.1 \%$ \\
\hline 2 & $10.6 \%$ & $12.4 \%$ & $14.5 \%$ \\
\hline $3+$ & $62.7 \%$ & $28.5 \%$ & $38.9 \%$ \\
\hline Expected OOPC* & $\$ 284$ & $\$ 350$ & $\$ 279$ \\
\hline Premium* & $\$ 135$ & $\$ 171$ & $\$ 132$ \\
\hline \multicolumn{4}{|l|}{ Base year } \\
\hline 2006 & $2,684,837$ & 29,283 & 194,292 \\
\hline 2007 & $2,888,710$ & 3184 & 193,470 \\
\hline 2008 & $3,217,796$ & 1745 & 207,787 \\
\hline 2009 & $3,280,679$ & 57,591 & 388,048 \\
\hline 2010 & $3,518,619$ & 140,735 & 420,090 \\
\hline
\end{tabular}

Source: Authors' analysis of Medicare enrollment data. Sample includes beneficiaries who gained eligibility and were not disabled. Excludes beneficiaries in employer-sponsored plans, and non-HMO, PPO, and PFFS plans. Excludes beneficiaries in contracts that experienced a merger or consolidation.

Stayer $=$ did not switch out of MA-PD contract

Terminated chooser $=$ switched out of MA-PD contract not offered in county in subsequent year

Voluntary switchers $=$ switched out of MA-PD contract offered in county in subsequent year

*In contract switching from. Excludes 2006 (data not available). 
Table 2. MA-PD switching rates, 2006-2010

\begin{tabular}{ccccc}
\hline & & & \multicolumn{2}{c}{ \% Switchers who are: } \\
Year & Beneficiaries & $\begin{array}{c}\text { \% Switch } \\
\text { Contracts }\end{array}$ & $\begin{array}{c}\text { Terminated } \\
\text { Choosers }\end{array}$ & $\begin{array}{c}\text { Voluntary } \\
\text { Switchers }\end{array}$ \\
\hline 2006 & $2,908,412$ & $8.8 \%$ & $11.4 \%$ & $88.6 \%$ \\
2007 & $3,085,364$ & $6.6 \%$ & $1.6 \%$ & $98.4 \%$ \\
2008 & $3,427,328$ & $6.3 \%$ & $0.8 \%$ & $99.2 \%$ \\
2009 & $3,726,318$ & $12.2 \%$ & $13.2 \%$ & $86.9 \%$ \\
2010 & $4,079,444$ & $13.8 \%$ & $25.1 \%$ & $74.9 \%$ \\
\hline
\end{tabular}

Authors' analysis of Medicare enrollment data in the 200 US counties with the largest elderly populations

Sample $=17,226,866$ person-years 
Table 3. Transitions from MA-PD to TM

Among beneficiaries Percent moving to TM

\begin{tabular}{ccc} 
Year & Terminated Choosers & Voluntary Switchers \\
\hline & & \\
$2006-07$ & $6.7 \%$ & $20.2 \%$ \\
$2009-10$ & $23.8 \%$ & $25.7 \%$ \\
$2010-11$ & $22.1 \%$ & $45.6 \%$ \\
\hline
\end{tabular}

Source: Authors' analysis of Medicare enrollment data 
Table 4a. Beneficiary transitions and enrollment outcomes, 2006-07

\begin{tabular}{|c|c|c|c|c|c|c|c|c|}
\hline & \multicolumn{2}{|c|}{ MA-HMO } & \multicolumn{2}{|c|}{ MA-PPO } & \multicolumn{2}{|c|}{ MA-PFFS } & \multirow[b]{2}{*}{$\begin{array}{l}\text { Stayers } \\
(7)\end{array}$} & \multirow{2}{*}{$\begin{array}{c}\text { Original } \\
\text { Choosers } \\
\text { (age 65) in } \\
2007 \\
\text { (8) }\end{array}$} \\
\hline & $\begin{array}{c}\text { Terminated } \\
\text { choosers } \\
(1) \\
\end{array}$ & $\begin{array}{c}\text { Voluntary } \\
\text { switchers } \\
\text { (2) }\end{array}$ & $\begin{array}{c}\text { Terminated } \\
\text { choosers } \\
\text { (3) } \\
\end{array}$ & $\begin{array}{c}\text { Voluntary } \\
\text { switchers } \\
\text { (4) }\end{array}$ & $\begin{array}{c}\text { Terminated } \\
\text { choosers } \\
\text { (5) }\end{array}$ & $\begin{array}{c}\text { Voluntary } \\
\text { switchers } \\
\text { (6) }\end{array}$ & & \\
\hline$N$ & 25,040 & 171,167 & 4,239 & 22,406 & 4 & 719 & $2,684,837$ & 164,857 \\
\hline In MA in 2007 & $94.8 \%$ & $80.5 \%$ & $85.0 \%$ & $75.1 \%$ & $75.0 \%$ & $58.4 \%$ & $100.0 \%$ & $\mathrm{n} / \mathrm{a}$ \\
\hline \multicolumn{9}{|l|}{ Within MA: } \\
\hline MA-HMO & $61.8 \%$ & $59.8 \%$ & $34.1 \%$ & $44.2 \%$ & $0.0 \%$ & $41.7 \%$ & $95.1 \%$ & $81.9 \%$ \\
\hline MA-PPO & $1.3 \%$ & $17.6 \%$ & $55.8 \%$ & $25.9 \%$ & $0.0 \%$ & $7.6 \%$ & $4.4 \%$ & $13.1 \%$ \\
\hline
\end{tabular}

Table 4b. Beneficiary transitions and enrollment outcomes, 2009-10

\begin{tabular}{|c|c|c|c|c|c|c|c|c|}
\hline & \multicolumn{2}{|c|}{ MA-HMO } & \multicolumn{2}{|c|}{ MA-PPO } & \multicolumn{2}{|c|}{ MA-PFFS } & \multirow[b]{2}{*}{ Stayers } & \multirow{2}{*}{$\begin{array}{l}\text { Original } \\
\text { choosers } \\
\text { (age 65) in } \\
2010\end{array}$} \\
\hline & $\begin{array}{c}\text { Terminated } \\
\text { choosers }\end{array}$ & $\begin{array}{l}\text { Voluntary } \\
\text { switchers }\end{array}$ & $\begin{array}{c}\text { Terminated } \\
\text { choosers }\end{array}$ & $\begin{array}{l}\text { Voluntary } \\
\text { switchers }\end{array}$ & $\begin{array}{c}\text { Terminated } \\
\text { choosers }\end{array}$ & $\begin{array}{l}\text { Voluntary } \\
\text { switchers }\end{array}$ & & \\
\hline$N$ & 3919 & 238,793 & 24,986 & 66,605 & 28,686 & 82,650 & $3,280,679$ & 229,608 \\
\hline Into TM in 2010 & $15.4 \%$ & $17.2 \%$ & $35.3 \%$ & $16.1 \%$ & $15.0 \%$ & $58.2 \%$ & $0.0 \%$ & $\mathrm{n} / \mathrm{a}$ \\
\hline \multicolumn{9}{|l|}{ Within MA: } \\
\hline MA-HMO & $62.0 \%$ & $68.7 \%$ & $56.4 \%$ & $50.4 \%$ & $30.8 \%$ & $44.0 \%$ & $88.3 \%$ & $76.1 \%$ \\
\hline MA-PPO & $21.8 \%$ & $25.6 \%$ & $37.3 \%$ & $42.0 \%$ & $36.6 \%$ & $47.7 \%$ & $9.6 \%$ & $20.5 \%$ \\
\hline MA-PFFS & $15.8 \%$ & $3.1 \%$ & $5.4 \%$ & $6.8 \%$ & $32.5 \%$ & $8.2 \%$ & $2.2 \%$ & $3.4 \%$ \\
\hline
\end{tabular}


Table 5. Enrollment outcomes for terminated choosers vs. weighted comparison group ${ }^{1}$

\begin{tabular}{|c|c|c|c|}
\hline & & $\begin{array}{c}\text { Terminated } \\
\text { choosers }\end{array}$ & $\begin{array}{c}\text { Weighted } \\
\text { comparison group }\end{array}$ \\
\hline \multicolumn{4}{|c|}{ Enrollment in next year } \\
\hline \multirow[t]{4}{*}{ Study Sample overall: } & $\mathrm{TM}$ & $11.1 \%$ & $2.6 \%$ \\
\hline & MA-HMO & $46.4 \%$ & $83.8 \%$ \\
\hline & MA-PPO & $12.8 \%$ & $2.5 \%$ \\
\hline & MA-PFFS & $29.5 \%$ & $11.0 \%$ \\
\hline \multicolumn{4}{|c|}{ Stratified by year and plan type: } \\
\hline \multicolumn{4}{|c|}{ Enrollment in 2007: } \\
\hline & TM & $5.2 \%$ & $1.3 \%$ \\
\hline \multirow[t]{5}{*}{ MA-HMO in 2006} & MA-HMO & $58.2 \%$ & $96.8 \%$ \\
\hline & MA-PPO & $1.3 \%$ & $0.2 \%$ \\
\hline & MA-PFFS & $35.2 \%$ & $1.6 \%$ \\
\hline & Enrollment in 2010: & & \\
\hline & TM & $15.4 \%$ & $1.3 \%$ \\
\hline \multirow[t]{5}{*}{ MA-HMO in 2009} & MA-HMO & $52.4 \%$ & $96.3 \%$ \\
\hline & MA-PPO & $18.5 \%$ & $1.8 \%$ \\
\hline & MA-PFFS & $13.3 \%$ & $0.6 \%$ \\
\hline & Enrollment in 2010: & & \\
\hline & TM & $17.5 \%$ & $7.9 \%$ \\
\hline \multirow[t]{3}{*}{ MA-PFFS in 2009} & MA-HMO & $30.5 \%$ & $15.2 \%$ \\
\hline & MA-PPO & $25.8 \%$ & $12.0 \%$ \\
\hline & MA-PFFS & $26.1 \%$ & $65.0 \%$ \\
\hline
\end{tabular}

\section{Notes:}

Study sample includes terminated choosers (enrollees in terminated HMO plans in 2006 or 2009, or in terminated PFFS plans in 2009) and propensity-score based weighted comparison group of non-terminated choosers)

${ }^{1}$ All differences in distribution of enrollment across plan types are statistically significant at $p<0.001$. 
Table 6. Susceptibility to nudges: Proportion of Terminated Choosers (TCs) who did NOT select a Part D plan

Did not enroll in

Part D

(\%)

All TCs with plan termination in 2009

TCs who chose a new MA plan

$1.7 \%$

TCs who went into traditional Medicare

$20.6 \%$

Did not

enroll in

Part D

(\%)

TCs with plan termination in $\mathbf{2 0 0 9}$ or $\mathbf{2 0 1 0}$

who went into traditional Medicare

Male

$24.0 \%$

Female

$19.2 \%$

Black

$38.7 \%$

Non-Black

$20.2 \%$

Age group:

65-69

$23.8 \%$

$70-74$

$20.7 \%$

75-79

$20.6 \%$

80-84

$19.8 \%$

$85+$

$16.4 \%$

Distribution of Median $\mathrm{HH}$ income in zip code

First quartile (lowest median $\mathrm{HH}$ income)

$24.5 \%$

Second quartile

$20.6 \%$

Third quartile

$20.4 \%$

Fourth quartile (highest median $\mathrm{HH}$ income)

$19.2 \%$

Source: Authors' analysis of Medicare enrollment data

Predicted enrollment based on logistic regression model controlling for

age, gender, race (black or non-black), median HH income in

zip code of residence, and year

Sample size: 44,286

$\mathrm{TC}=$ terminated chooser 


\section{References}

Abaluck, J., and J. Gruber. Choice Inconsistencies among the Elderly: Evidence from Plan Choice in the Medicare Part D Program. American Economic Review 2011; 101 (4): 1180-210.

Abaluck J and Gruber J. Evolving Choice Inconsistencies in Choice of Prescription Drug Insurance. NBER Working Paper 19163 June 2013.

Afendulis CC, Landrum MB, Chernew ME. The Impact of the Affordable Care Act on Medicare Advantage Plan Availability and Enrollment. Health Services Research 2012; 47(6): 2339-2352.

Afendulis CC, Sinaiko AD, Frank RG. Dominated Choices and Medicare Advantage Enrollment. NBER Working Paper no.20181, 2014.

Agarwal S, Driscoll J, Gabaix X and Laibson D. The age of reason: Financial decisions over the lifecycle. In American Law and Economic Association Annual Meetings, 2008.

Armour S. Republicans Question Viability of Co-Ops. Wall Street Journal (online) [New York, NY] 25 Feb 2016

Arrow K. Uncertainty and the welfare economics of medical care. American Economic Review 1963; 53(5): 941-973.

Beshears, J., J. J. Choi, D. Laibson, and B. C. Madrian. 2008. How Are Preferences Revealed? Journal of Public Economics 92 (8-9): 1787-94.

Beshears, J., J. J. Choi, D. Laibson, and B. C. Madrian. The Importance of Default Options for Retirement Savings Options. In Brown, Liebman and Wise, eds, Social Security Policy in a Changing Environment Chicago, IL, University of Chicago Press, 2009. p 167-195.

Camerer C, Loewenstein G, and Prelec D. Neuroeconomics: How Neuroscience can Inform Economics. Journal of Economic Literature 2005; 43(1):9-64.

Cox C, Claxton G, Levitt L. "Analysis of Insurer Participation in 2016 Marketplaces" Kaiser Family Foundation Issue Brief. Nov 03, 2015; http://kff.org/health-reform/issue-brief/analysis-ofinsurer-participation-in-2016-marketplaces/ (Accessed on Apr 20 2015).

Cox C and Semanskee A. "Analysis of UnitedHealth Group's Premiums and Participation in ACA Marketplaces." Kaiser Family Foundation Issue Brief. April 18, 2016.

Cox C and Semanskee A. "Preliminary Data on Insurer Exits and Entrants in 2017 Affordable Care Act Marketplaces." Kaiser Family Foundation Data Note. August 2016.

Cutler, D., and Reber S. Paying for health insurance: the trade-off between competition and adverse selection. Quarterly Journal of Economics 1998; 113(2): 443-466.

Dafny L, Hendel I and Wilson N. "Narrow Networks on the Health Insurance Exchanges: What Do They Look Like and How Do They Affect Pricing" The American Economic Review 105(5): 110-114.

Dafny L, Gruber J and Ody C. "More Insurers Lower Premiums: Evidence from Initial Pricing in the Health Insurance Marketplaces." The American Journal of Health Economics 2015; 1(1): 5381. 
Frank RG. (2007) Behavioral Economics and Health Economics. In Behavioral Economics and Its Applications. Diamond P, and Vartiainen H. (Eds.) Princeton: Princeton University Press.

Gabel JR, Whitmore H, Stromberg S et al. "Analysis Finds No Nationwide Increase in Health Insurance Marketplace Premiums" Commonwealth Fund Blog [blog on the Internet]. 2014 Dec 22 [cited 2016 Apr 20]. Available from:

http://www.commonwealthfund.org/publications/blog/2014/dec/zero-inflation-nationwide-formarketplace-premiums

Gold, M, Achman L, Mittler J, and Stevens B. 2004 "Monitoring Medicare+Choice: What Have We Learned? Findings and Operational Lessons for Medicare Advantage," Washington DC: Mathematica Policy Research, Doct No PR04-43

Goldstein, D. G., E. J. Johnson, A. Herrmann, and M. Heitman. "Nudge Your Customers Toward Better Choices." Harvard Business Review, December 2008: 99-105.

Hanoch, Y., and T. Rice. Can Limiting Choice Increase Social Welfare? The Elderly and Health Insurance. Milbank Quarterly 2006; 84 (1): 37-73.

Hirano, Keisuke and Imbens, Guido W. Estimation of causal effects using propensity score weighting: An application to data on right heart catheterization. Health Services and Outcomes Research Methodology 2001; 2:259-278.

Johnson EJ and Goldstein DG. Do Defaults Save Lives? Science, 2003; 302:1338-1339.

Jost T. Updated Renewal and Discontinuation Notices, Auto-Reenrollment, And Other ACA Developments. Health Affairs Blog September 5, 2016; www.healthaffairs.org (accessed December 4, 2016).

Keeney RL and Raiffa H. Decisions with Multiple Objectives: Preferences and Value Trade-offs Cambridge [England], New York, N.Y.: Cambridge University Press, 1976.

Ketcham JD, Lucarelli C, Miravete EJ, and Roebuck MC. Sinking, Swimming or Learning to Swim in Medicare Part D. American Economic Review 2012; 102(6): 2639-2673.

Ketcham JD, Lucarelli C, and Powers CA. Paying Attention or Paying Too Much in Medicare Part D. American Economic Review 2015; 105(1): 204-233.

King R. Colorado to Close Obamacare Co-Op. Washington Examiner (online). October 16, 2015.

Kowalski A. "The Early Impact of the Affordable Care Act, State by State," Brookings Papers on Economic Activity, Economic Studies Program, The Brookings Institution, vol. 49(2 (Fall 2014)), pages 277-355.

Kurth T, Walker AM, Glynn RJ, et al. Results of multivariable logistic regression, propensity matching, propensity adjustment, and propensity-based weighting under conditions of nonuniform effect. Am J Epidemiol 163:262-270, 2006.

Kuye IO, Frank RG, McWilliams JM. Cognition and Take-Up of Subsidized Drug Benefits by Medicare Beneficiaries. JAMA Intern Med 2013; doi:10.1001/jamainternmed.2013.845. 
La Monica PR. "UnitedHealthcare to Exit Most Obamacare Exchanges." CNN Money April 19, 2016 http://money.cnn.com/2016/04/19/investing/unitedhealthcare-obamacare-exchangesaca/index.html (Accessed April 20, 2016)

Madrian, B. C., and D. F. Shea. 2001. The Power of Suggestion: Inertia in 401(k) Participation and Savings Behavior. Quarterly Journal of Economics 116:1149-87.

McWilliams, J. M., C. C. Afendulis, T. G. McGuire, and B. E. Landon. 2011. Complex Medicare Advantage Choices May Overwhelm Seniors-Especially Those with Impaired Decision Making. Health Affairs 30 (9): 1786-94.

McWilliams, J. M., J. Hsu, and J. P. Newhouse. 2012. New Risk-adjustment System Was Associated with Reduced Favorable Selection in Medicare Advantage. Health Affairs 31 (12): 2630-40.

McWilliams JM, Meara E, Zaslavsky AM, Ayanian JZ. Use of health services by previously uninsured Medicare beneficiaries. New England Journal of Medicine 2007a;357:143-53. PMID: 17625126

Medicare Payment Advisory Commission. 2000. Report to the Congress: Improving Risk Adjustment in Medicare. Washington, DC: Medicare Payment Advisory Commission.

Medicare Payment Advisory Commission. 2007. Report to Congress: Medicare Payment Policy. Washington, DC: Medicare Payment Advisory Commission.

Medicare Payment Advisory Commission. 2009. Report to the Congress: Improving Incentives in the Medicare Program. Washington, DC: Medicare Payment Advisory Commission.

Medicare Payment Advisory Commission. 2010. Report to Congress: Medicare Payment Policy. Washington, DC: Medicare Payment Advisory Commission.

Medicare Payment Advisory Commission. 2011. Report to Congress: Medicare Payment Policy. Washington, DC: Medicare Payment Advisory Commission.

Medicare Payment Advisory Commission. 2016. Report to Congress: Medicare Payment Policy. Washington, DC: Medicare Payment Advisory Commission.

Newhouse, J. P., M. Price, J. Huang, J. M. McWilliams, and J. Hsu. 2012. Steps to Reduce Favorable Risk Selection in Medicare Advantage Largely Succeeded, Boding Well for Health Insurance Exchanges. Health Affairs 31 (12): 2618-28.

Pear R. Some Policies Get More Time in Health Shift. The New York Times March 6, 2014, p A1.

Pear R. Aetna to Pull Back From Public Health Care Exchanges. The New York Times August 16, 2016.

Physician Payment Review Commission. Annual Report to Congress, 1996. Washington, DC: Physician Payment Review Commission. 
Riley, G., and C. Zarabozo. Trends in the Health Status of Medicare Risk Contract Enrollees. Health Care Financing Review 2006; 28 (2): 81-95.

Samuelson, W., and R. Zeckhauser. Status Quo Bias in Decision Making." Journal of Risk and Uncertainty 1988; 1:7-59.

Sinaiko AD, Afendulis CC, and Frank RG. Enrollment in Medicare Advantage Plans in MiamiDade County: Evidence of Status Quo Bias? Inquiry 2013.

Smith CN, Goldstein D, Johnson EJ. Smart defaults: From hidden persuaders to adaptive helpers (Working Paper, INSEAD, 2009); available at http://papers.ssrn.com.ezpprod1.hul.harvard.edu/sol3/papers.cfm?abstract id=1116650 .

Thaler R and Sunstein C. Nudge: Improving Decisions about Health, Wealth and Happiness (New York, NY: Penguin Books, 2009).

Zhang Y, Baik SH, and Newhouse JP. Use of Intelligent Assignment to Medicare Part D Plans for People With Schizophrenia Could Produce Substantial Savings. Health Affairs 2015; 34(3): 455-460.

Zhang Y, Donohue JM, Lave JR, ODonnel G, Newhouse JP. The Effect of Medicare Part D on Drug and Medical Spending. N Engl J Med 2009; 361:52-61 


\section{Appendix}

\section{A.1. Medicare Advantage contract-level out-of-pocket cost data}

We obtained previously determined estimates of the out-of-pocket costs (OOPC), including premiums, associated with each MA-PD plan option. The Centers for Medicare and Medicaid Services (CMS) calculated these estimates by taking medical utilization data for a standard population of Medicare beneficiaries and applying the coverage and cost-sharing rules specific to each plan to these utilization data to determine the average monthly out-of-pocket costs expected for a beneficiary enrolling in that plan. ${ }^{21}$ These calculations were conducted separately for five self-reported health-status groups and for six age groups. To merge these estimates with our contract-level enrollment data for each age group in each county in a given year, we averaged OOPC estimates for the five health-status groups within plans, and then averaged the OOPC plan estimates for all plans under a given MA-PD contract. We applied county contract-level enrollment data to calculate an enrollment-weighted average OOPC of being in an MA-PD contract for each age group and year for all contracts available in each county.

${ }^{21}$ The standard population was a two-year sample of TM-enrolled respondents to the Medicare Current Beneficiary Survey. This estimate assumes that the quantity of services consumed does not vary with the differing cost-sharing rules across the MA plans. 
A.2. Demographic Characteristics of Terminated and Non-Terminated Choosers

2006 HMO

\begin{tabular}{ccccc} 
& \multicolumn{2}{c}{ Unweighted } & \multicolumn{2}{c}{ Weighted } \\
& Non-Terminated & Terminated & Non-Terminated & Terminated \\
$\mathrm{N}$ & 2723831 & 21953 & 2723831 & 21953 \\
black & $8.0 \%$ & $2.5 \%$ & $2.4 \%$ & $2.5 \%$ \\
male & $41.4 \%$ & $39.3 \%$ & $38.9 \%$ & $39.3 \%$ \\
a7074 & $27.3 \%$ & $30.3 \%$ & $30.2 \%$ & $30.3 \%$ \\
a7579 & $23.1 \%$ & $25.2 \%$ & $25.3 \%$ & $25.2 \%$ \\
a8084 & $15.2 \%$ & $14.7 \%$ & $15.0 \%$ & $14.7 \%$ \\
a85 & $9.0 \%$ & $8.6 \%$ & $8.7 \%$ & $8.6 \%$ \\
a7074male & $11.8 \%$ & $12.3 \%$ & $12.1 \%$ & $12.3 \%$ \\
a7074black & $2.4 \%$ & $0.7 \%$ & $0.6 \%$ & $0.7 \%$ \\
a7579male & $9.7 \%$ & $10.4 \%$ & $10.3 \%$ & $10.4 \%$ \\
a7579black & $1.7 \%$ & $0.7 \%$ & $0.7 \%$ & $0.7 \%$ \\
a8084male & $5.9 \%$ & $5.4 \%$ & $5.4 \%$ & $5.4 \%$ \\
a8084black & $1.0 \%$ & $0.4 \%$ & $0.4 \%$ & $0.4 \%$ \\
a85male & $3.1 \%$ & $2.8 \%$ & $2.8 \%$ & $2.8 \%$ \\
a85black & $0.6 \%$ & $0.2 \%$ & $0.2 \%$ & $0.2 \%$
\end{tabular}

\section{HMO}

Unweighted

Non-Terminated Terminated

$\mathrm{N}$

black

male

a7074

a7579

a8084

a85

a7074male

a7074black

a7579male

a7579black

a8084male

a8084black

a85male

a85black
3133379

$8.5 \%$

$41.7 \%$

$25.2 \%$

$21.9 \%$

$15.2 \%$

$10.1 \%$

$10.9 \%$

$2.4 \%$

$9.3 \%$

$1.8 \%$

$6.1 \%$

$1.1 \%$

$3.5 \%$

$0.7 \%$
3919

$12.5 \%$

$44.3 \%$

$25.5 \%$

$19.0 \%$

$12.0 \%$

$7.3 \%$

$11.5 \%$

$3.1 \%$

$8.1 \%$

$2.5 \%$

$5.2 \%$

$1.0 \%$

$2.6 \%$

$0.6 \%$
Weighted

Non-Terminated Terminated

3199973

3919

$12.3 \%$

$12.5 \%$

$44.5 \%$

$44.3 \%$

$25.6 \%$

$25.5 \%$

$18.9 \%$

$19.0 \%$

$12.0 \%$

$12.0 \%$

$7.3 \%$

$7.3 \%$

$11.6 \%$

$11.5 \%$

$3.1 \%$

$3.1 \%$

$8.0 \%$

$8.1 \%$

$2.5 \%$

$2.5 \%$

$5.2 \%$

$5.2 \%$

$1.0 \%$

$1.0 \%$

$2.6 \%$

$2.6 \%$

$0.6 \%$

$0.6 \%$ 
2009 PFFS

\begin{tabular}{ccccc} 
& \multicolumn{2}{c}{ Unweighted } & \multicolumn{2}{c}{ Weighted } \\
$\mathrm{N}$ & Non-Terminated & Terminated & Non-Terminated & Terminated \\
black & 148736 & 17852 & 148736 & 17852 \\
male & $6.5 \%$ & $7.3 \%$ & $7.0 \%$ & $7.3 \%$ \\
a7074 & $42.4 \%$ & $43.3 \%$ & $43.7 \%$ & $43.3 \%$ \\
a7579 & $24.2 \%$ & $24.9 \%$ & $24.9 \%$ & $24.9 \%$ \\
a8084 & $19.3 \%$ & $16.3 \%$ & $16.1 \%$ & $16.3 \%$ \\
a85 & $13.5 \%$ & $10.6 \%$ & $10.5 \%$ & $10.6 \%$ \\
a7074male & $8.5 \%$ & $6.2 \%$ & $6.1 \%$ & $6.2 \%$ \\
a7074black & $10.7 \%$ & $11.0 \%$ & $11.1 \%$ & $11.0 \%$ \\
a7579male & $1.7 \%$ & $2.1 \%$ & $2.0 \%$ & $2.1 \%$ \\
a7579black & $8.2 \%$ & $7.1 \%$ & $7.1 \%$ & $7.1 \%$ \\
a8084male & $1.3 \%$ & $1.2 \%$ & $1.2 \%$ & $1.2 \%$ \\
a8084black & $5.4 \%$ & $4.1 \%$ & $4.1 \%$ & $4.1 \%$ \\
a85male & $0.8 \%$ & $0.7 \%$ & $0.7 \%$ & $0.7 \%$ \\
a85black & $2.8 \%$ & $2.0 \%$ & $2.0 \%$ & $2.0 \%$ \\
& $0.5 \%$ & $0.4 \%$ & $0.4 \%$ & $0.4 \%$
\end{tabular}

